(C) 2019. This manuscript version is made available under the CC-BY-NC-ND 4.0 license http://creativecommons.org/ licenses/by-nc-nd/4.0/

\title{
Assessing Data Assimilation Frameworks for Using Multi-mission Satellite Products in a Hydrological Context
}

\author{
M. Khaki ${ }^{\mathrm{a}, 1}$, I. Hoteit ${ }^{\mathrm{c}}$, M. Kuhn ${ }^{\mathrm{a}}$, E. Forootan $^{\mathrm{d}}$, J. Awange $^{\mathrm{a}}$ \\ ${ }^{a}$ School of Earth and Planetary Sciences, Spatial Sciences, Curtin University, Perth, Australia. \\ ${ }^{b}$ School of Engineering, University of Newcastle, Callaghan, New South Wales, Australia. \\ ${ }^{c}$ King Abdullah University of Science and Technology, Thuwal, Saudi Arabia. \\ ${ }^{d}$ School of Earth and Ocean Sciences, Cardiff University, Cardiff, UK.
}

\begin{abstract}
With a growing number of available datasets especially from satellite remote sensing, there is a great opportunity to improve our knowledge of the state of the hydrological processes via data assimilation. Observations can be assimilated into numerical models using dynamics and datadriven approaches. The present study aims to assess these assimilation frameworks for integrating different sets of satellite measurements in a hydrological context. To this end, we implement a traditional data assimilation system based on the Square Root Analysis (SQRA) filtering scheme and the newly developed data-driven Kalman-Takens technique to update the water components of a hydrological model with the Gravity Recovery And Climate Experiment (GRACE) terrestrial water storage (TWS), and soil moisture products from the Advanced Microwave Scanning Radiometer - Earth Observing System (AMSR-E) and Soil Moisture and Ocean Salinity (SMOS) in a 5-day temporal scale. While SQRA relies on a physical model for forecasting, the Kalman-Takens only requires a trajectory of the system based on past data. We are particularly interested in testing both methods for assimilating different combination of the satellite data. In most of the cases, simultaneous assimilation of the satellite data by either standard SQRA or Kalman-Takens achieves the largest improvements in the hydrological state, in terms of the agreement with independent in-situ measurements. Furthermore, the Kalman-Takens approach performs comparably well to dynamical method at a fraction of the computational cost.
\end{abstract}

Keywords: Data assimilation, Data-driven, Kalman-Takens, Hydrological modelling, SQRA.

Email address: Mehdi.Khaki@postgrad.curtin.edu.au (M. Khaki) 


\section{Introduction}

The study of terrestrial water storage (TWS) and different water compartments, such as soil moisture, groundwater, and surface water storage, is essential because of their roles in the environment, hydroclimate impacts, and human life as a major fresh water resource. In this regard, hydrological models provide a unique opportunity to enhance our understandings of hydrological processes within land areas. The models have been used to analyze the spatiotemporal variations of hydrological components (e.g., Wooldridge and Kalma, 2001; Doll et al., 2003; Huntington, 2006; Coumou and Rahmstorf, 2012; van Dijk et al., 2013). Nevertheless, there are factors such as inaccurate inputs and forcing fields, data deficiencies (e.g., limited ground-based observations), and imperfect modeling that impose a degree of uncertainties in models' simulations (van Dijk et al., 2011; Vrugt et al., 2013). High resolution (spatially and temporally) satellite remotely sensed observations of different water compartments can be assimilated to improve models performances (Schumacher et al., 2016; Khaki et al., 2017a). Accordingly, various approaches have been put forward to efficient incorporation of observations into the models (e.g., Bishop et al., 2001; Kalnay, 2003; Tippett et al., 2003; Sauer, 2004; Evensen, 2004; Dreano et al., 2015).

Data assimilation provides a framework to integrate models simulations with new observations. When a physics-based model is available, data assimilation techniques constrain the model state with available observations in order to bring its outputs closer to the data according to their uncertainties (Bertino et al., 2003; Hoteit et al., 2012). This approach has been widely implemented in hydrological studies (e.g., Reichle et al., 2002; Seo et al., 2003; Vrugt et al., 2005; Weerts and El Serafy, 2006; Neal et al., 2009; Giustarini et al., 2011; Khaki et al., 2018a,b; Tangdamrongsub et al., 2018). In other cases, where the physical processes of the studied system are not available or perfectly understood, data-driven (or non-parametric) approaches may provide reliable alternatives (e.g., Sauer, 2004; Tandeo et al., 2015; Dreano et al., 2015; Hamilton et al., 2016; Lguensat et al., 2017). Both dynamical and data-driven modeling approaches have their own advantageous and disadvantageous. Traditionally, data assimilation systems were implemented based on a physical model, which can lead to a better redistribution of increments between state variables but generally requires intensive computations in realistic applications (Tandeo et al., 2015). A data-driven model, on the other hand, only relies on data and their associated errors with no or limited knowledge of physical processes but computationally can be significantly less demanding. 
The main aim of this contribution is to assess the performance of these frameworks for assimilating different combinations of multiple satellite remote sensing products within a hydrological context. For this purpose, we use an ensemble-based sequential technique, the Square Root Analysis (SQRA) filtering scheme (Evensen, 2004) from dynamical, a modified version of the recently developed data-driven approach, Kalman-Takens filter (Hamilton et al., 2016) from the data-driven approach. Khaki et al. (2017a) recently studied the performance of various standard data assimilation schemes and showed that SQRA is highly capable of assimilating TWS data into a hydrological model (see also Schumacher et al., 2016). The method has also been found to outperform other existing filters, e.g., addressing the sampling error in covariance matrix, especially for the small-size ensembles and an efficient resampling process (see, e.g., Whitaker and Hamill, 2002; Nerger, 2004; Hoteit et al., 2015; Khaki et al., 2017a).

In addition to SQRA filter, a modified version of the recently developed data-driven approach, Kalman-Takens filter (Hamilton et al., 2016), is applied. Takens method has been used in various studies for non-parametric time series predictions (see, e.g., Packard et al., 1980; Takens, 1981; Sauer et al., 1991; Sauer, 2004). Hamilton et al. (2016) used this method and developed a new model-free filter for data assimilation when the physical model is not available. The KalmanTakens method relies only on observations and a trajectory of the model to build a data-driven surrogate of the model dynamics, which is required to forecast the system state at a fraction of the computational time. The idea of using the model trajectory has also been used in Tandeo et al. (2015) and Lguensat et al. (2017) to simulate the dynamics of complex systems. All these studies have shown that the data-driven approach can perform well, sometimes comparable to a standard data assimilation.

Here, for the first time, the application of SQRA and Kalman-Takens are investigated for assimilating various observation sets including terrestrial water storage (TWS) derived from the Gravity Recovery And Climate Experiment (GRACE), soil moisture products from the Advanced Microwave Scanning Radiometer - Earth Observing System (AMSR-E) and Soil Moisture and Ocean Salinity (SMOS) into a hydrological model, and their combination. Several studies suggest that assimilating these products can successfully constrain the mass balance of hydrological models (e.g., Zaitchik et al., 2008; Thomas et al., 2014; Eicker et al., 2014; Reager et al., 2015; Khaki et al., 2017b,c). In addition, various studies validate AMSR-E (e.g., Draper et al., 2009; Mladenova et al., 2011) and SMOS (e.g., Peischl et al., 2012; Jing et al., 2018) soil moisture products globally and 
suggest their capability for accurately reflecting soil moisture variations of the surface top soil layer. It has also been shown by Renzullo et al. (2014) and Tian et al. (2017) that assimilation of these products can effectively improve model soil moisture simulations over Australia. Different scenarios are tested here to achieve the best estimates of the water storage components. This involves using SQRA and the Kalman-Takens filters for integrating TWS and soil moisture observations separately and simultaneously and comparing their impact on different water compartments. Two different domains of Murray-Darling and Mississippi basins are selected for testing subject to the availability of in-situ measurements for evaluation of the results.

The rest of the manuscript is organized as follows. Datasets and model are described in Section 2. The two filtering techniques are presented in Section 3 while Sections 4 and 5 analyze and discuss the results, respectively. The study is then concluded in Section 6 .

\section{Materials}

\subsection{Data assimilation (forecast step)}

\subsubsection{W3RA}

Here we use $1^{\circ} \times 1^{\circ}$ grid-distributed biophysical model of the World-Wide Water Resources Assessment (W3RA) for the period from January 2003 to December 2012. W3RA is based on the Australian Water Resources Assessment system (AWRA) model, which is provided by the Commonwealth Scientific and Industrial Research Organisation (CSIRO) to monitor, represent and forecast Australian terrestrial water cycles (http://www.wenfo.org/wald/data-software/). Forcing fields of minimum and maximum temperature, downwelling short-wave radiation, and precipitation from Princeton University are used in this study (Sheffield et al., 2006, http://hydrology.princeton.edu). These $1^{\circ} \times 1^{\circ}$ daily forcing sets are only used to run the model. It is important to note that the inclusion of rain-gauge based product (e.g., Global Precipitation Climatology Centre; GPCC, Schneider et al., 2008) can potentially improve the model's performance (see, e.g., Massari et al., 2018). This study, however, uses Princeton Global Meteorological Forcing dataset (Sheffield et al., 2006, PRIN;), which has been shown, e.g., by Awange et al. (2016) to exhibit similar patterns of correlation to GPCC in some regions. The model parameters include effective soil parameters, water holding capacity and soil evaporation, relating greenness and groundwater recession, and saturated area to catchment characteristics (van Dijk et al., 2013). The water balance of a top 
soil, shallow soil and deep soil compartment, as well as groundwater and surface water dynamics, are simulated at grid resolution, in which each cell is modeled independently of its neighbors (van Dijk, 2010). Water (e.g., from rainfall) redistribute between these compartments starting from the top soil layer and entering the deep root layer through capillary rise from groundwater. It then leaves the column through soil evaporation, extraction by shallow- and deep-rooted vegetation, or drainage into the groundwater store (Renzullo et al., 2014). Model state in the present study includes the W3RA water storages in the top, shallow and deep soil moisture, vegetation, snow, surface, and groundwater. Figure 1 summarizes the data and methodology (as it will discussed in Section 3) used in this study.

\subsection{Data assimilation (analysis step)}

\subsubsection{GRACE TWS}

The GRACE spherical harmonic coefficients with their full error information are acquired from the ITSG-Grace2014 gravity field model (Mayer-Gurr et al., 2014). Here, we used Stokes' coefficients up to degree and order 90 (approximate spatial resolution of $\sim 300$ by $300 \mathrm{~km}$ at the equator) covering 2003 to 2013. The following steps have been taken before converting the spherical harmonics to TWS. Degrees 1 and 2 are replaced with improved estimates since the GRACEestimates are not very reliable (Cheng and Tapley, 2004; Swenson et al., 2008). The L2 gravity fields are then converted into 5-day $3^{\circ} \times 3^{\circ}$ TWS fields (suggested by Khaki et al., 2017b, for data assimilation purposes) following Wahr et al. (1998). Note that colored/correlated noise in products is reduced by the Kernel Fourier Integration (KeFIn) filter proposed by Khaki et al. (2018c), which also accounts for signal attenuations and leakage effects caused by smoothing. The KeFIn filter works through a two-step post-processing algorithm. The first step mitigates the measurement noise and the aliasing of unmodelled high-frequency mass variations, and the second step contains an efficient kernel to decrease the leakage errors (see also Khaki et al., 2018e).

\subsubsection{Soil Moisture}

We use AMSR-E to derive soil moisture products. AMSR-E measures surface brightness temperature at twelve channels. This is highly correlated to surface soil moisture content $(0-2 \mathrm{~cm}$ depth) and has been used to produce global data products of surface soil moisture content using satellite-based radiometer instruments (Njoku et al., 2003). Daily measurements of surface soil 


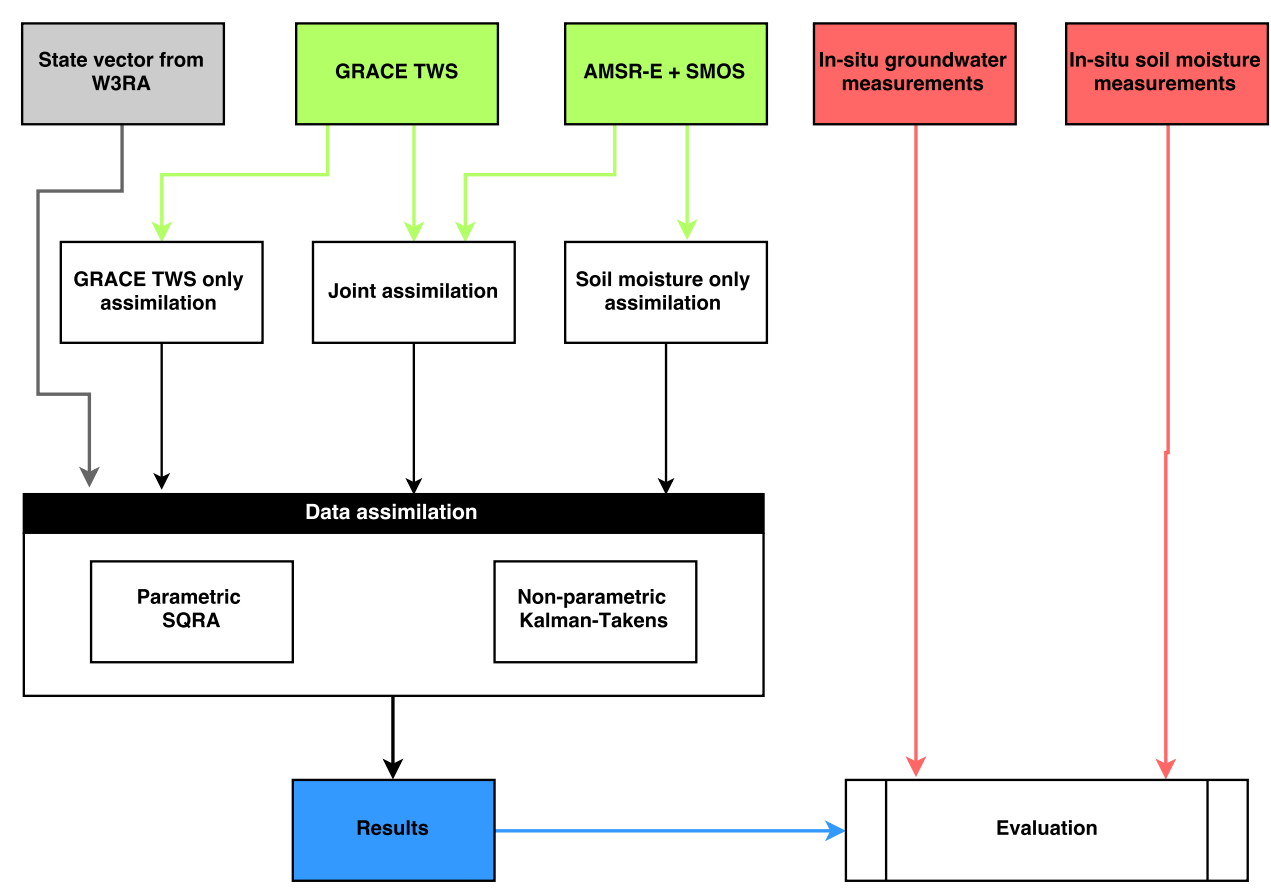

Figure 1: A schematic illustration of the implemented data assimilation frameworks and data used.

moisture from descending passes (see, e.g., De Jeu and Owe, 2003; Su et al., 2013) with a spatial resolution of $0.25^{\circ} \times 0.25^{\circ}$ covering the period between 2003 and 2011 from the gridded Level-3 land surface product $(\mathrm{Njoku}, 2004)$ are rescaled to a 5 -day $1^{\circ} \times 1^{\circ}$ for the present study.

We further use Level 3 CATDS (Centre Aval de Traitement des Donnees SMOS) soil moisture data (Jacquette et al., 2010) from ESA's SMOS Earth Explorer mission. SMOS Microwave Imaging Radiometer using Aperture Synthesis (MIRAS) radiometer measures microwave emissions from Earth's surface to map land soil moisture $(\sim 0-5 \mathrm{~cm}$ depth $)$. Here we use ascending passes of the satellite subject to their higher agreement to in-situ measurements (see, e.g., Draper et al., 2009; Jackson and Bindlish, 2012). The soil moisture data temporal and spatial resolutions are three days and about $50 \mathrm{~km}$, respectively. Similar to AMSR-E, SMOS data are rescaled to a 5-day (2011-2013) $1^{\circ} \times 1^{\circ}$ scale

An important step is required to prepare soil moisture products for data assimilation and to remove the bias between the model simulations and observations. These measurements are mainly used to constrain the state variability, and not its absolute values. Several studies have applied different methods to rescale soil moisture measurements (see, e.g., Reichle and Koster, 
2004; Kumar et al., 2012). Here, we use cumulative distribution function (CDF) matching for rescaling the observations (Reichle and Koster, 2004; Drusch et al., 2005). CDF matching relies on the assumption that the difference between observed soil moisture and that of the model is stationary and guarantees that the statistical distribution of both time series is the same (Draper et al., 2009; Renzullo et al., 2014).

\subsection{Validation dataset}

\subsubsection{Water Fluxes}

For the sake of result assessment, water flux observations are also acquired. These include monthly precipitation data from TRMM-3B43 products in $0.25^{\circ} \times 0.25^{\circ}$ spatial resolution $(\mathrm{TRMM}$, 2011; Huffman et al., 2007), MOD16 evaporation data with eight days temporal resolution and one km spatial resolution from the University of Montana's Numerical Terradynamic Simulation group (Mu et al., 2011), and water discharge data from the Global Runoff Data Centre (GRDC) and United States Geological Survey (USGS), and the Australian Bureau of Meteorology under the Water Regulations (2008). All these products are rescaled into $0.25^{\circ} \times 0.25^{\circ}$ and to the same temporal resolution of data assimilation observations.

\subsubsection{In-situ data}

In-situ groundwater and soil moisture measurements are used to examine the results. Groundwater measurements are acquired from USGS for the Mississippi Basin and from New South Wales Government (NSW) for the Murray-Darling Basin. Specific yields are required to convert well-water levels to groundwater storage variations, which are unknown. Thus, following Strassberg et al. (2007), we use an average (0.15) of specific yields range from 0.1 to 0.3 as suggested by Gutentag et al. (1984) over the Mississippi basin, and 0.13 specific yield from the range between 0.115 and 0.2 as suggested by the Australian Bureau of Meteorology (BOM) and Seoane et al. (2013) for the Murray-Darling basin. In-situ soil moisture data are obtained from the International Soil Moisture Network and the moisture-monitoring network over the Mississippi and Murray-Darling basins, respectively. The distribution of gauge stations over the study areas is presented in Figure 2. 

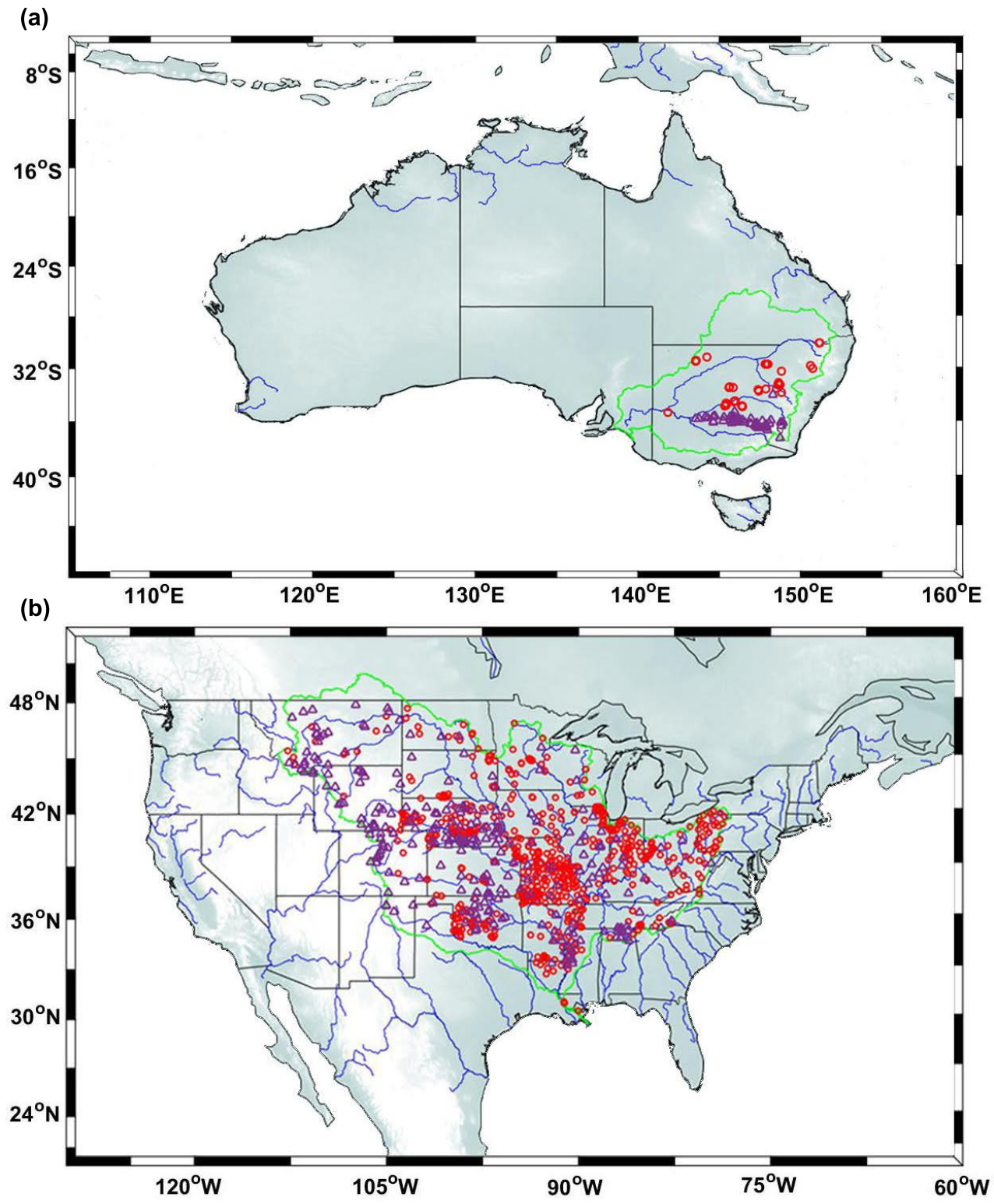

Figure 2: Locations of Murray-Darling (a) and Mississippi (b) basins. A distribution of groundwater (circle) and soil moisture (triangle) in-situ stations are also displayed.

\section{Data Assimilation}

The model state includes top, shallow and deep soil moisture, vegetation, snow, surface, and groundwater storages for both SQRA and the Kalman-Takens approaches. Except for groundwater and surface storages, all the other components are simulated with two hydrological response units (HRU) of tall (deep-rooted vegetation) and short (shallow-rooted vegetation), leading to 12 state 
variables $(5 \times 2+2)$ at each grid cell. These state variables are updated using GRACE TWS and satellite soil moisture observations through data assimilation. The assimilation procedure includes two step,

- Forecast step. $\mathbf{x}_{t-1}$ and its error covariance evolve through the time $(t)$, the next assimilation step, using the dynamical model $(\mathcal{M})$.

- Analysis step. The forecast state $\left(\mathbf{x}_{t}^{f}\right)$ is updated by the observation $\mathbf{y}_{t}$.

Here, both selected filters, i.e., SQRA and Kalman-Takens, use the same analysis step. The main difference between the two methods is that while a dynamics-driven model advances the state estimate forward in time for forecasting, a data-driven technique uses a model proxy to compute the forecast. This process can be achieved using the non-parametric delay-coordinate approach (see details in Section 3.1.2).

\subsection{Forecast step}

\subsection{1. $S Q R A$}

The model state $\left(\mathbf{x}_{t-1}\right)$ is integrated in time through a dynamical model (Eq.1). Given an ensemble member from time $t-1, \mathbf{x}=\left\{\mathbf{x}_{\mathbf{i}}, \quad \mathbf{i}=\mathbf{1}, \ldots, \mathbf{n}\right\}$ the forecast state in SQRA can be calculated using Eq.1. Observations at the assimilation time $(t)$ are represented by $\left\{\mathbf{y}_{t}\right\}_{t=0}^{T} \in \mathbb{R}^{n_{y}}$, which are related to the state through a dynamical state-space system of the form,

$$
\left\{\begin{array}{l}
\mathbf{x}_{\mathbf{t}}^{f}=\mathcal{M}_{t-1}\left(\mathbf{x}_{t-1}\right)+\boldsymbol{\nu}_{t} \\
\mathbf{y}_{t}=\mathbf{H}_{t} \mathbf{x}_{\mathbf{t}}^{f}+\mathbf{w}_{t}
\end{array}\right.
$$

where ' $f$ ' stands for forecast (and ' $a$ ' in the following for analysis) and $\mathbf{x}^{f}$ refers to the forecast state at time t. $\mathcal{M}($.$) is the model operator with the noise processes of \boldsymbol{\nu}=\left\{\boldsymbol{\nu}_{t}\right\}_{t}$ drawn from $N(0, \mathbf{Q})$ with covariance matrix $\mathbf{Q}$, and $\mathbf{H}$ is the design matrix with $\mathbf{w}=\left\{\mathbf{w}_{t}\right\}_{t}$ drawn from $N(0, \mathbf{R})$ with covariance matrix $R$. Accordingly, the forecast state $\left(\mathbf{P}_{t}^{f}\right)$ in SQRA can be derived by,

$$
\mathbf{P}_{t}^{f}=\mathcal{M}_{t-1} \mathbf{P}_{\mathbf{t}-\mathbf{1}} \mathcal{M}_{\mathbf{t}-\mathbf{1}}^{\mathbf{T}}+\mathbf{Q}_{\mathbf{t}} .
$$




\subsubsection{The Kalman-Takens}

The Kalman-Takens filter, initially proposed by Hamilton et al. (2016), is applied here after a few modification. As mentioned, the main different between this filter and SQRA is forecasting step while both methods use similar analysis scheme. The Kalman-Takens filter replaces model equations $\mathcal{M}$ with a local proxy $\tilde{\mathbf{f}}$ based on data. The method considers delay-coordinate vector (to replace the dynamical model for advancing the state forward in time. This delay-coordinate can be built using $\left[\mathbf{x}_{t}^{\mathbf{o}}, \mathbf{x}^{\mathbf{o}}{ }_{t-1}, \ldots, \mathbf{x}_{t-d}^{\mathbf{o}}\right]$, where $\mathbf{x}^{\mathbf{o}}$ is the training data for reconstructing the system and $d$ indicates the number of temporal delays.

In the original form of the method, it relies on observable $\mathbf{y}_{t}$ to create the delay-coordinate vector. Here, instead, we use a model trajectory to create the delay-coordinate vector. This is motivated by the fact that we are interested in updating the different water storage components while GRACE produces the summation of these compartments. We, therefore, assume that a trajectory generated by the model is readily available. In the present study the water storage components from W3RA, i.e., the open-loop top, shallow and deep soil moisture, vegetation, snow, surface, and groundwater are used to create the delay-coordinate vector.

Using the $N$ nearest neighbors within a set of training data based on a given Euclidean distance, the delay-coordinate vectors at $t+1, \mathbf{x}_{t+1}^{\mathbf{o}}, \mathbf{x}_{t+1}^{\mathbf{o} 2}, \ldots, \mathbf{x}_{t+1}^{\mathbf{o}}$, can be used to construct the local model for predicting $\mathbf{x}_{t+1}$. To this end, a locally constant model following Hamilton et al. (2016) is used (see also Hamilton et al., 2017). This model in its most basic form can be assumed as an average of the nearest neighbors, e.g.,

$$
\tilde{f}\left(\mathbf{x}_{t}\right)=\left[\frac{\mathbf{x}_{t+1}^{\mathbf{o} 1}, \mathbf{x}_{t+1}^{\mathbf{o} 2}, \ldots, \mathbf{x}_{t+1}^{\mathbf{o}}}{N}, \mathbf{x}_{t}^{\mathbf{o}}, \ldots, \mathbf{x}_{t-d+1}^{\mathbf{o}}\right]
$$

Once the local proxy $\tilde{f}$ is generated, the forecasting step can be carried out to estimate $\mathbf{x}^{f}$. Afterwards, the analysis step of SQRA is applied to reach $\mathbf{x}^{a}$ (see Section 3.2). Note that different values for the number of neighbors $N$ and delays $d$ were considered and their results are compared against in-situ measurement. 


\subsection{Analysis step}

The analysis step in SQRA involves first updating the forecast ensemble-mean $\left(\overline{\mathbf{x}}^{f}=\right.$ $\left.\frac{1}{N} \sum_{i=1}^{N} \mathbf{x}_{\mathbf{i}}^{f}\right)$ as,

$$
\overline{\mathbf{x}}^{a}=\overline{\mathbf{x}}^{f}+\mathbf{K}\left(\mathbf{y}-\mathbf{H} \overline{\mathbf{x}}^{f}\right),
$$

with Kalman Gain $(\mathbf{K})$

$$
\mathbf{K}=\mathbf{P}^{f}(\mathbf{H})^{T}\left(\mathbf{H P}^{f}(\mathbf{H})^{T}+\mathbf{R}\right)^{-1},
$$

and

$$
\mathbf{P}^{f}=\frac{1}{N-1} \sum_{i=1}^{N}\left(\mathbf{x}_{\mathbf{i}}^{f}-\overline{\mathbf{x}}^{f}\right)\left(\mathbf{x}_{\mathbf{i}}^{f}-\overline{\mathbf{x}}^{f}\right)^{T},
$$

where $\overline{\mathbf{x}}^{a}$ is the analysis state, and the error covariance associated with observations $(\mathbf{y})$ is denoted by $\mathbf{R}$. For each satellite observation set, a different $\mathbf{R}$ is used. Full error information of the L2 potential coefficients for each month are provided for GRACE data (cf. Section 2.2.1). These products are then converted from the GRACE coefficients to TWS errors following Schumacher et al. (2016). Regarding soil moisture observations, various error values are tested to monitor their impacts on data assimilation by comparing the results with independent measurements (cf. Section 2.3.2). This allows us to obtain optimum error values for soil moisture part of observation error covariance. Accordingly, $\mathbf{R}$ is assumed to be diagonal with an error standard deviation of $0.04\left(\mathrm{~m}^{3} \mathrm{~m}^{-3}\right)$ for SMOS (suggested by Leroux et al., 2016) and $0.05\left(\mathrm{~m}^{3} \mathrm{~m}^{-3}\right)$ for AMSR-E (suggested by De Jeu et al., 2008). It is worth mentioning that using spatially varying error information rather than the constant error assumption can lead to different results and potentially optimal data assimilation performance. However, providing such an information is difficult and out of the scope of our study, so we use the estimated optimal constant errors. Furthermore, we assume that GRACE data are uncorrelated from both SMOS and AMSR-E observations. An ensemble of anomalies, representing the deviation of the analysis ensemble members from the ensemble mean $\left(\overline{\mathbf{x}}^{a}\right)$ is then sampled by,

$$
\mathbf{A}^{a}=\mathbf{A}^{f} \mathbf{V} \sqrt{\mathbf{I}-\mathbf{\Sigma}^{T} \mathbf{\Sigma} \Theta^{T}}
$$


where $\mathbf{A}^{f}=\left[\mathbf{A}_{1}{ }^{f} \ldots \mathbf{A}_{N}{ }^{f}\right]$ is the ensemble of forecast anomalies $\left(\mathbf{A}_{i}{ }^{f}=\mathbf{x}_{\mathbf{i}}{ }^{f}-\overline{\mathbf{x}}^{f}\right), \boldsymbol{\Sigma}$ and $\mathbf{V}$ are obtained from the singular value decomposition (SVD) of $\mathbf{A}^{f}\left(\mathbf{A}^{f}=\mathbf{U} \boldsymbol{\Sigma} \mathbf{V}^{T}\right)$, and $\boldsymbol{\Theta}$ is a random orthogonal matrix for redistributing the ensemble variance (Evensen, 2007; Hoteit et al., 2002). These perturbations are then added to the analysis state to form a new ensemble by,

$$
\mathbf{x}_{\mathbf{i}}^{a}=\overline{\mathbf{x}}^{a}+\mathbf{A}_{i}^{a}, \quad i=1, \cdots, N .
$$

$\mathbf{x}_{\mathbf{i}}{ }^{a}$ is then used to start the next forecasting cycle by integrating the $\mathbf{x}_{\mathbf{i}}{ }^{a}$ with the dynamical model to compute the next $\mathbf{x}_{\mathbf{i}}{ }^{f}$ (cf. Evensen, 2004, 2007; Khaki et al., 2017a).

\subsection{Filter Implementation}

In order to generate the initial ensemble, we perturb the forcing fields according to their error characteristics. This is done using a Gaussian multiplicative error of $30 \%$ for precipitation, an additive Gaussian error of $50 \mathrm{Wm}^{-2}$ for the shortwave radiation, and a Gaussian additive error of $2^{\circ} \mathrm{C}$ for temperature (Jones et al., 2007; Renzullo et al., 2014). Monte Carlo sampling of multivariate normal distributions with errors representing the standard deviations of the forcing sets are then used to produce the ensemble (see details in Renzullo et al., 2014; Khaki et al., 2017a). The produced ensemble of perturbations of 72 members (suggested by Khaki et al., 2017a) are then integrated with model between 2000 and 2003 to generate an ensemble at the beginning of the assimilation period.

To mitigate for the standard issues related to the rank deficiency and the underestimation of the error covariance matrix of ensemble-based Kalman filters, which are due to the limited number of ensemble members and ensemble spread collapse (Anderson , 2001; Houtekamer and Mitchell, 2001), ensemble inflation and the Local Analysis (LA) scheme (Evensen, 2003; Ott et al., 2004) applied. The ensemble inflation method uses a small coefficient to separately inflate prior ensemble deviation from the ensemble-mean and increases their variations (Anderson et al., 2007). Here, we use a constant factor ( $S=1.12$; Anderson , 2001; Khaki et al., 2017b) to inflate the ensemble perturbations as,

$$
\mathbf{x}^{\prime f}=S\left(\mathbf{x}^{\mathbf{f}}-\overline{\mathbf{x}}^{\mathbf{f}}\right)+\overline{\mathbf{x}}^{\mathbf{f}}
$$

with $X^{\prime f}$ representing the new forecast state, which contains the inflated ensemble perturbation. 
Table 1: A summary of the applied data assimilation scenarios. Note that all water storages includes top soil, shallow soil, deep soil water, snow, vegetation, surface, and groundwater storages.

\begin{tabular}{|c|c|c|c|c|}
\hline $\begin{array}{l}\text { Assimilation } \\
\text { case }\end{array}$ & $\begin{array}{l}\text { Filtering } \\
\text { technique }\end{array}$ & $\begin{array}{l}\text { Observation } \\
\text { type }\end{array}$ & State vector & Updated states \\
\hline Case 1 & SQRA & $\begin{array}{l}\text { GRACE } \\
\text { TWS }\end{array}$ & All water storages & Storages summation \\
\hline Case 2 & SQRA & $\begin{array}{l}\text { AMSR-E + } \\
\text { SMOS }\end{array}$ & $\begin{array}{l}\text { Only soil storages } \\
\text { (top, shallow, } \\
\text { deep) }\end{array}$ & $\begin{array}{l}\text { Scaling top soil layer (by field } \\
\text { capacity value) }\end{array}$ \\
\hline Case 3 & SQRA & $\begin{array}{l}\text { Joint obser- } \\
\text { vations }\end{array}$ & All water storages & $\begin{array}{l}\text { Storages summation by ob- } \\
\text { served TWS + Scaling top soil } \\
\text { layer by observed soil mea- } \\
\text { surements }\end{array}$ \\
\hline Case 4 & $\begin{array}{l}\text { Kalman- } \\
\text { Takens }\end{array}$ & $\begin{array}{l}\text { GRACE } \\
\text { TWS }\end{array}$ & All water storages & Storages summation \\
\hline Case 5 & $\begin{array}{l}\text { Kalman- } \\
\text { Takens }\end{array}$ & $\begin{array}{l}\text { AMSR-E + } \\
\text { SMOS }\end{array}$ & $\begin{array}{l}\text { Only soil storages } \\
\text { (top, shallow, } \\
\text { deep) }\end{array}$ & $\begin{array}{l}\text { Scaling top soil layer (by field } \\
\text { capacity value) }\end{array}$ \\
\hline Case 6 & $\begin{array}{l}\text { Kalman- } \\
\text { Takens }\end{array}$ & $\begin{array}{l}\text { Joint obser- } \\
\text { vations }\end{array}$ & All water storages & $\begin{array}{l}\text { Storages summation by ob- } \\
\text { served TWS + Scaling top soil } \\
\text { layer by observed soil mea- } \\
\text { surements }\end{array}$ \\
\hline
\end{tabular}

LA, on the other hand, spatially limits the impact of given measurements in the analysis step to the points located within a certain distance. In using LA, at each horizontal grid point $(m, n)$, with $m$ and $n$ representing geographic latitude and longitude directions, respectively, the selected measurements close to the grid point contribute to the SQRA filtering process. This means that only particular state variables close to the point $(m, n)$ within an assumed distance and corresponding observations at the same locations are used in the assimilation process (see details in Khaki et al., 2017b).

Figure 1 presents a summary of the data integration framework for the dynamics- and datadriven approaches. Different experimental scenarios in terms of methodology and assimilated observations are examined. Table 1 outlines the conducted experiments, indicating, in particular, the assimilated observations types and the model used for each case.

\section{Results}

In this section, we first analyze the results of different data assimilation methods and scenarios on the forecast estimates. This allows examining how each case incorporates different 
observations and how these effects are reflected in forecast state variables. Note that this is not a result validation process and the purpose of this analysis is to show the capability of different scenarios for forecast improving based on assimilated observation. We later evaluate the final results by comparing them against the reference fields. It is also worth mentioning that different scenarios are considered regarding the number of neighbors $N$ (i.e., 2-40) and also the number of delays $d$ (i.e., 1-25) in the Kalman-Takens implementation. It is found that increasing the number of neighbors can improve the approximation of training data for a particular point to a certain extent (due to the existing spatial correlations). However, selecting $N$ too large can cause a rapid growth of errors, which is related to the effect of over-smoothing the training step. This is different for delays $d$, where much larger errors are present for smaller values that underestimate temporal variabilities in the data. Accordingly, we set $N=14$ and $d=11$ as they lead to the best assimilation performances for the entire experiment (see more details in Khaki et al., 2018d).

Figure 3a and Figure 3b plot correlations between the estimated TWS by each filtering method and GRACE TWS over Murray-Darling and Mississippi basins, respectively. Correlations between the filters estimates and observed soil moistures (from satellites) are also depicted respectively in Figure 3c and Figure 3d for the Murray-Darling and Mississippi basins. Note that the correlation values are calculated for all grid points within the basins (at 95\% confidence interval) and their averages at forecast steps for each case is presented in Figure 3.

The minimum correlation values are found for the open-loop run while all the other cases demonstrate higher correlations. Comparable performances are achieved by SQRA and KalmanTakens methods. This is clear from the close correlations for cases 1 and 4, cases 2 and 5 , and cases 3 and 6, regardless of whether GRACE TWS only, soil moisture measurements only, or both of them are assimilated. Based on Figure 3, one can see that both SQRA and Kalman-Takens that assimilate GRACE TWS and satellite soil moisture data simultaneously, i.e., case 3 and case 6, exhibit the highest correlations over the Murray-Darling and Mississippi basins. This can be seen for both sets of observations, i.e., GRACE TWS and soil moisture measurements. In cases where only one data is assimilated, e.g., cases 1, 2, 4, and 5, the largest correlation is generally achieved between the observables and assimilated observations. For example, as it is expected, a larger correlation between GRACE TWS and TWS estimates from SQRA and Kalman-Takens are achieved when GRACE data is assimilated compared to the cases when satellite soil moisture is assimilated. Similarly, the correlation between the estimated and observed soil moisture fields are 


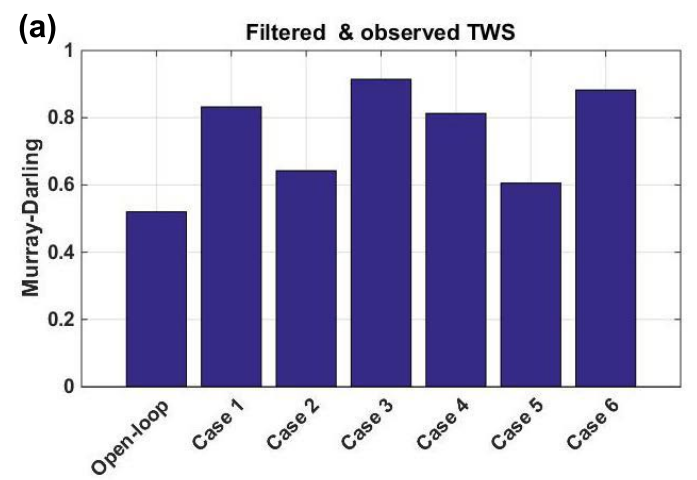

(b)

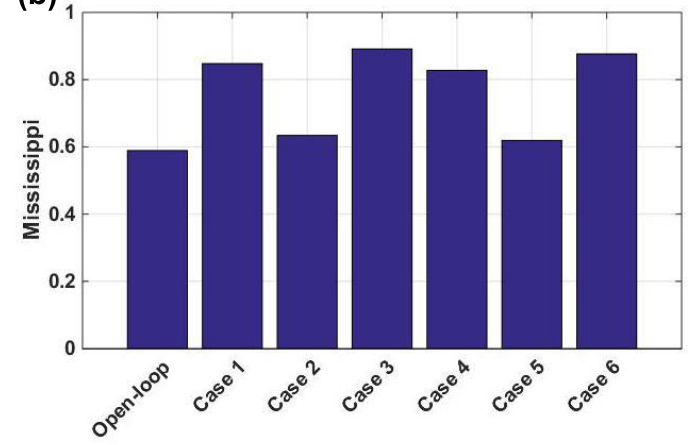

(c)

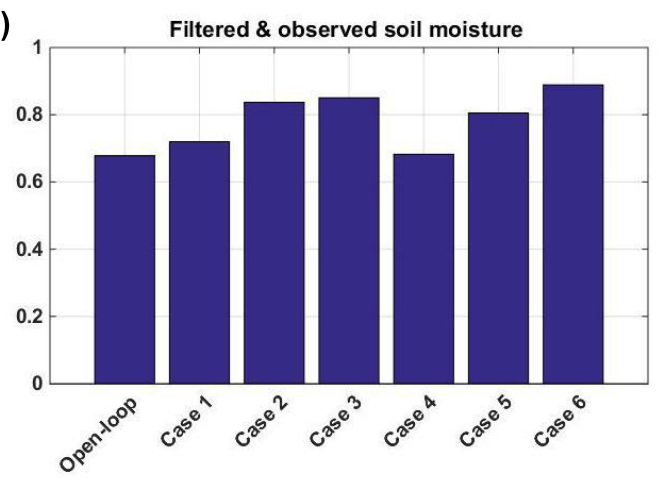

(d)

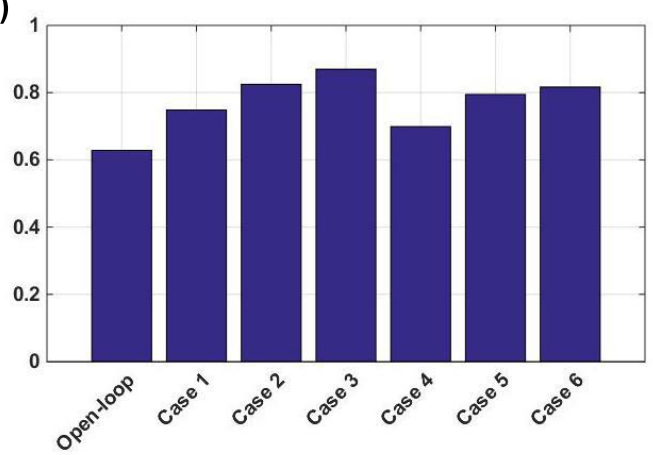

Figure 3: Average correlations between observable variables and assimilated data sets for each case and open-loop at forecast steps. (a) and (b) indicate the correlations between estimated and observed TWS over Murray-Darling and Mississippi basins, respectively. The correlations between estimated top layer soil moisture and observations (SMOS+AMSR-E) are displayed in (c) for Murray-Darling basin and (d) for Mississippi basin.

the largest for cases 2 and 5 over both basins. Interestingly, the results show that assimilating even only one of the observation data sets, e.g., either GRACE TWS or soil moisture products, can also improve the correlations for non-observable variables. This demonstrates the efficient impacts of data assimilation on all state variables.

The achieved correlation improvement, however, is largest for the simultaneous assimilation cases, where both GRACE TWS and soil moisture products are assimilated. This suggests that simultaneous data assimilation can lead to better forecasts. From Figure 3, the simultaneous assimilation in cases 3 and 6 , lead to larger correlations between the filters estimates of soil moisture and TWS, and the observations over both basins compared to the case only one observation is assimilated. In general, in most of the simultaneous assimilation cases, SQRA performs better compared to the Kalman-Takens filter. Nevertheless, the correlation values show that this is a marginal superiority for TWS correlations while in soil moisture correlation over the Murray-Darling the Kalman-Takens filter reaches larger correlation values. To better analyze the impact of data assim- 
ilation, results of these two simultaneous assimilation cases over Murray-Darling and Mississippi basins are plotted in Figure 4. Both cases successfully reduce the misfits between the estimates and GRACE TWS as well as soil moisture observations for both basins. Major improvements can also be seen compared to open-loop time series. This figure along with Figure 3 illustrate that assimilating both observation sets can better balance the effects of observations between all state variables. It is particularly of interest to see that the computationally less demanding Kalman-Takens performs closely to the dynamical method, and even better in some cases.

To better show how each method can reduce the misfits between observations and state variables, two extreme events including an above average precipitation, mainly caused by El Niño Southern Oscillation (ENSO; see, e.g., Boening et al., 2012; Forootan et al., 2016) for the period of 20102012 over the Murray-Darling basin and the El Niño events in 2010 over the Mississippi basin (e.g., Munoz and Dee, 2004) are selected. This experiment is undertaken to monitor each case performance for reflecting the above events in the system. Average TWS estimates from each case are compared with GRACE TWS in Figure 5, where the first row shows precipitation and GRACE TWS time series while the second row demonstrates differences between assimilated observations and filter estimates. It can be seen that least errors are calculated for simultaneous assimilation using SQRA and to a lesser degree simultaneous assimilation by the Kalman-Takens method. This shows that both methods perform well in reducing the discrepancy between model and observations in such extreme anomalies. GRACE data assimilation using SQRA and Kalman-Takens appear to be more successful to capture these events that satellite soil moisture only assimilation.

\subsection{Groundwater evaluation}

To assess the results of each data assimilation scenario, independent groundwater in-situ measurements are used. Estimated groundwater in-situ measurements are spatially interpolated to the location of model grid points using the nearest neighbor (the closest four grid values) to compare with groundwater time series by each method. Error time series, as a difference between in-situ and estimated groundwater values, are then calculated. For every station, we compute the Root-Mean-Squared Error (RMSE), standard deviation (STD) of error time series and also the correlation between in-situ measurements and filters results. Figure 6 displays the results corresponding all assimilation cases over the Murray-Darling and Mississippi basins. One can see that the simultaneous data assimilation using both filtering schemes perform closely and better than 


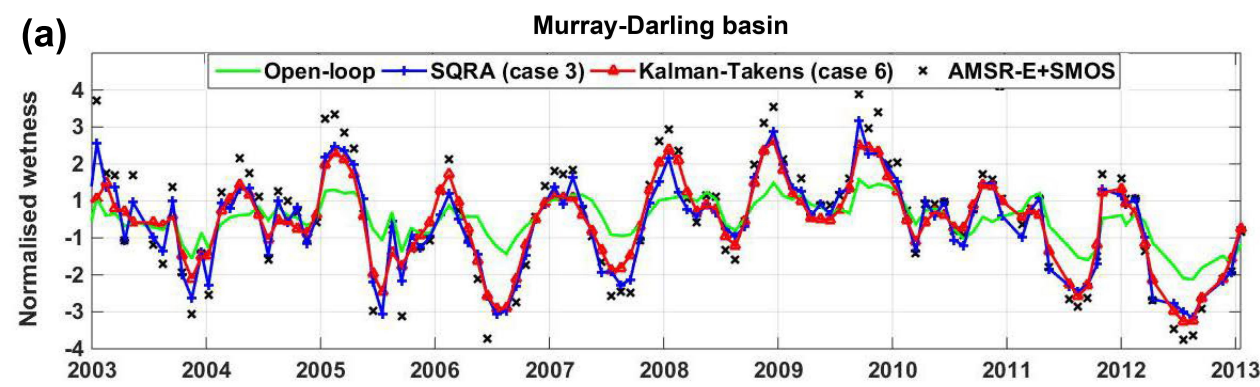

(b)

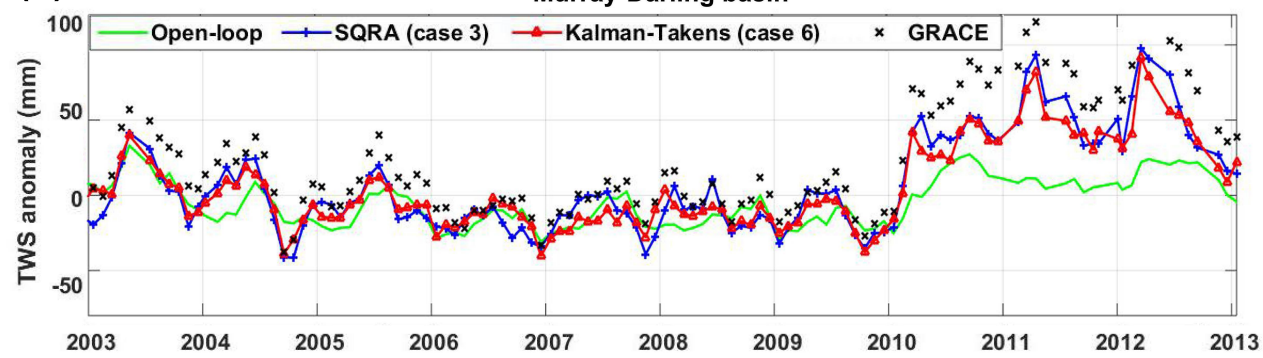

(c)

Mississippi basin

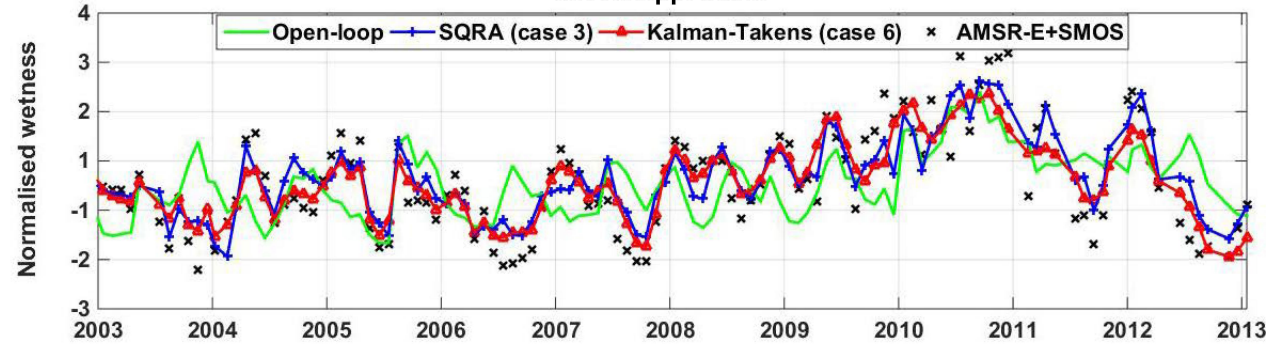

(d)

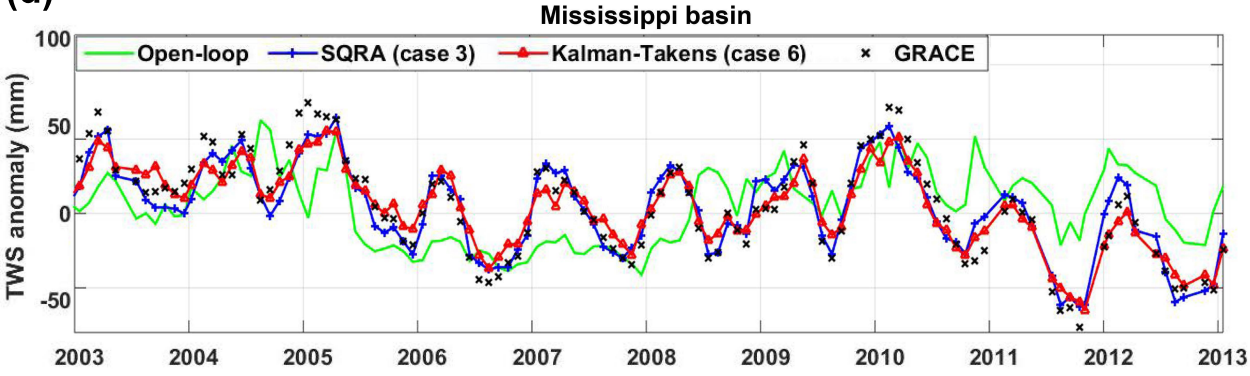

Figure 4: (a) and (b) show soil moisture and TWS variation time series of simultaneous data assimilations using SQRA and Kalman-Takens over the Murray-Darling, respectively. (c) and (d) are the same as (a) and (b) but for the Mississippi basins. The figure also contains average time series of open-loop and observations.

other cases. The least RMSE values are achieved from these cases compared to other scenarios. After these, assimilating only GRACE TWS using SQRA, and the Kalman-Takens filter, obtain smaller RMSE and STD values. This figure further demonstrates the capability of Kalman-Takens for assimilating multiple observation data sets, leading to comparable results to the traditional 

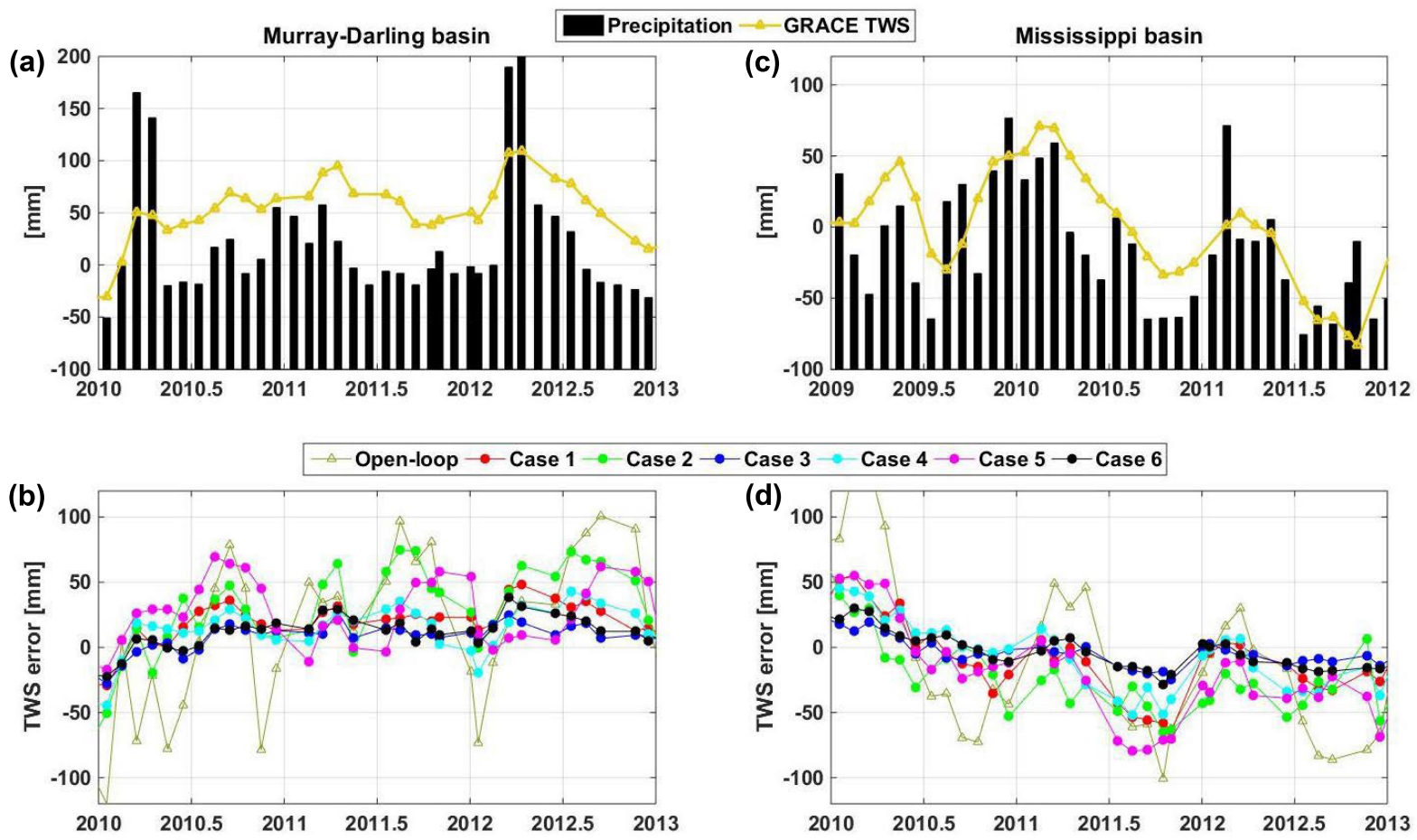

Figure 5: (a) and (b) represent the average rainfall and GRACE TWS variations, respectively, over the MurrayDarling basin. The average rainfall and GRACE TWS variations over the Mississippi basin are shown in (c) and (d), respectively. Note that rainfall bar plots are shifted $(-100 \mathrm{~mm})$ for a better presentation. Second row: the differences between GRACE TWS and TWS estimated by each data assimilation case, as well as the open-loop run for the corresponding basins.

data assimilation system. Detailed results of all tested cases are presented in Table 2. Note that a significance test for the correlation coefficients is applied using t-distribution. The estimated t-value and the distribution at 0.05 significant level are used to calculate p-value. The correlations with p-values that lie under $5 \%$ are assumed to be significant.

Results in Table 2 demonstrates improved estimates after assimilation for all the cases in comparison to the open-loop, 25\% RMSE reduction and 28\% correlations (on average). The best performance is achieved from case 3 (simultaneous assimilation using dynamics method) for the Murray-Darling basin and from case 6 (simultaneous assimilation using Kalman-Takens) for the Mississippi basin. In most of the cases, more RMSE reductions are obtained over the Mississippi basin, especially using Kalman-Takens. The better performance of Kalman-Takens in cases 4 and 6 in comparison to the cases 1 and 3 within the Mississippi basin could be attributed to model errors that can degrade the performance of the parametric approach that relies on the model algorithms. 
(a)

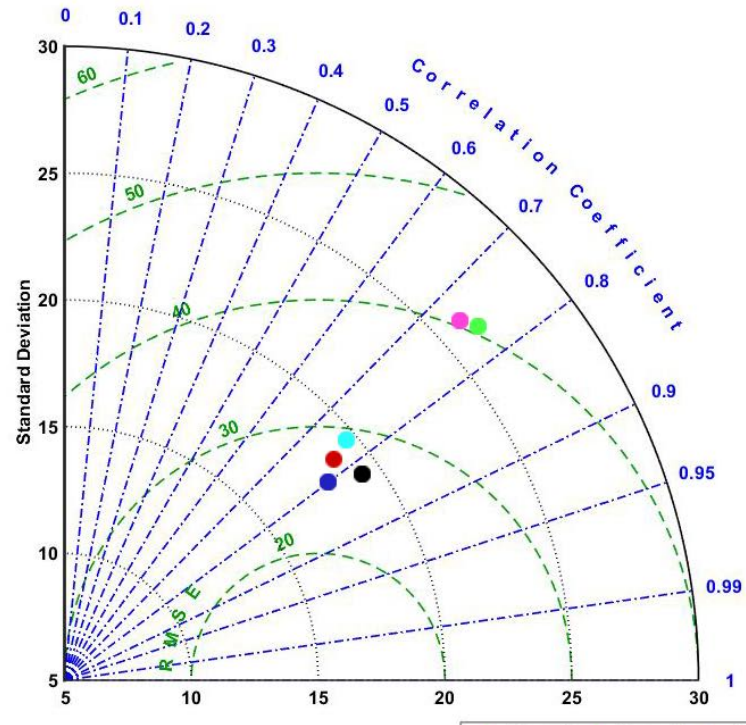

(b)

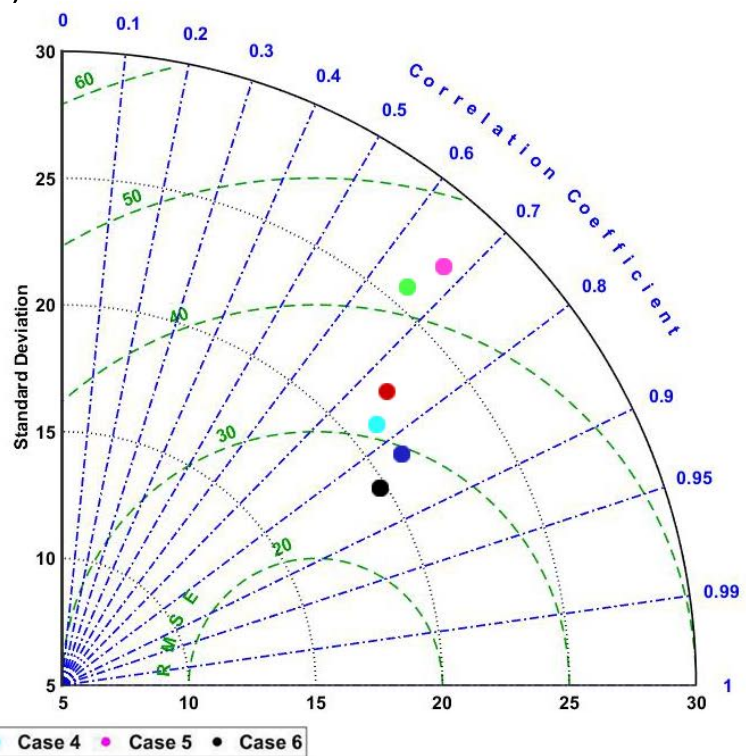

Figure 6: Comparison between different data assimilation cases over the Murray-Darling (a) and Mississippi (b) basins. Groundwater estimates by filters are compared with in-situ measurements to calculate RMSE, STD, and correlation.

GRACE TWS suggests larger effects on RMSE reduction than satellite soil moisture products. Simultaneous assimilation using either SQRA or Kalman-Takens results in the least RMSEs. Over Murray-Darling, assimilation of GRACE TWS only leads to better results in comparison to assimilating only soil moisture measurements. This, however, is different for the Mississippi basin, where assimilating only soil moisture observations in case 2 provides better results. On the other hand, Kalman-Takens leads slightly to better results when assimilating GRACE TWS.

Overall, based on Table 2, simultaneous data assimilation gives the best groundwater estimates with larger correlations and less RMSE with respect to the in-situ groundwater measurements. The Kalman-Takens results are not only close to those of SQRA but also in some cases show larger improvements. More importantly, the Kalman-Takens method is found to be less demanding computationally, i.e., $\sim 6$ times faster for the study period, compared to SQRA. Knowing that both methods exploit similar analysis scheme, the main reason for such superiority refers to faster forecasting in the Kalman-Takens filter, which is based on a local approximation (using the proxy model) and requires much less computation than a physics-based model. 
Table 2: Summary of statistical values derived from implemented methods using the groundwater in-situ measurements. For each method the RMSE average and its range $( \pm \mathrm{XX})$ at the $95 \%$ confidence interval is presented. The improvements in the analysis state RMSE estimates are calculated using the in-situ measurements in comparison to the forecast states and open-loop run.

\begin{tabular}{|c|c|c|c|c|c|c|}
\hline \multirow[b]{2}{*}{ Method } & \multicolumn{2}{|c|}{ Murray-Darling basin } & \multicolumn{2}{|c|}{ Mississippi basin } & \multicolumn{2}{|c|}{ RMSE Reduction (\%) } \\
\hline & RMSE $(\mathrm{mm})$ & Correlation & RMSE $(\mathrm{mm})$ & Correlation & Murray-Darling & Mississippi \\
\hline Case 1 & $26.90 \pm 6.32$ & 0.78 & $33.54 \pm 7.56$ & 0.73 & 36.42 & 27.59 \\
\hline Case 2 & $40.72 \pm 7.29$ & 0.75 & $42.08 \pm 8.24$ & 0.65 & 3.76 & 9.15 \\
\hline Case 3 & $24.85 \pm 5.74$ & 0.80 & $29.51 \pm 6.18$ & 0.82 & 41.27 & 36.29 \\
\hline Case 4 & $28.68 \pm 7.18$ & 0.76 & $31.72 \pm 7.06$ & 0.77 & 32.21 & 31.52 \\
\hline Case 5 & $40.09 \pm 8.92$ & 0.74 & $44.29 \pm 8.15$ & 0.68 & 5.25 & 4.38 \\
\hline Case 6 & $25.78 \pm 5.46$ & 0.82 & $27.11 \pm 6.25$ & 0.84 & 39.07 & 40.47 \\
\hline
\end{tabular}

\subsection{Soil moisture evaluation}

We further examine the assimilation results by comparing the soil moisture estimates with independent in-situ measurements. Here, we only investigate the correlation between the estimate and in-situ data because converting the assimilation outputs (as column water storage measured in $\mathrm{mm}$ ) into volumetric units similar to the in-situ soil moisture measurements is likely to introduce a bias (Renzullo et al., 2014). Estimated soil moisture at the model top layer is compared with 0-8 $\mathrm{cm}$ measurements over the Murray-Darling basin and 0-10 $\mathrm{cm}$ over the Mississippi basin. We also use 0-30 $\mathrm{cm}$ and 0-50 $\mathrm{cm}$ measurements over the Murray-Darling and Mississippi basins, respectively, to examine the summation of the model top, shallow and a portion of deep-root soil layers. Lastly, 0-90 cm (for Murray-Darling) and 0-100 cm (for Mississippi) soil measurements are compared with the summation of the model top, shallow, and deep soil moisture layers. Similar to groundwater assessment, estimated soil moisture time series are spatially interpolated at the locations of the insitu measurements using the nearest neighbor. The correlation is then calculated between estimated and in-situ time series and the results are demonstrated in Figure 7.

It is clear from Figure 7 that assimilating observations, especially GRACE TWS, mainly affect deep soil moisture layers and improve their estimates. The least improvement can be seen for the model top layer. Improvements with respect to the open-loop are achieved in all scenarios. These improvements, however, are different for each filtering method. Overall, assimilating only soil moisture measurements (as in cases 2 and 5) achieves better results in comparison to GRACE only assimilation (as in cases 1 and 4) over top layers. Simultaneous data assimilation using either SQRA 

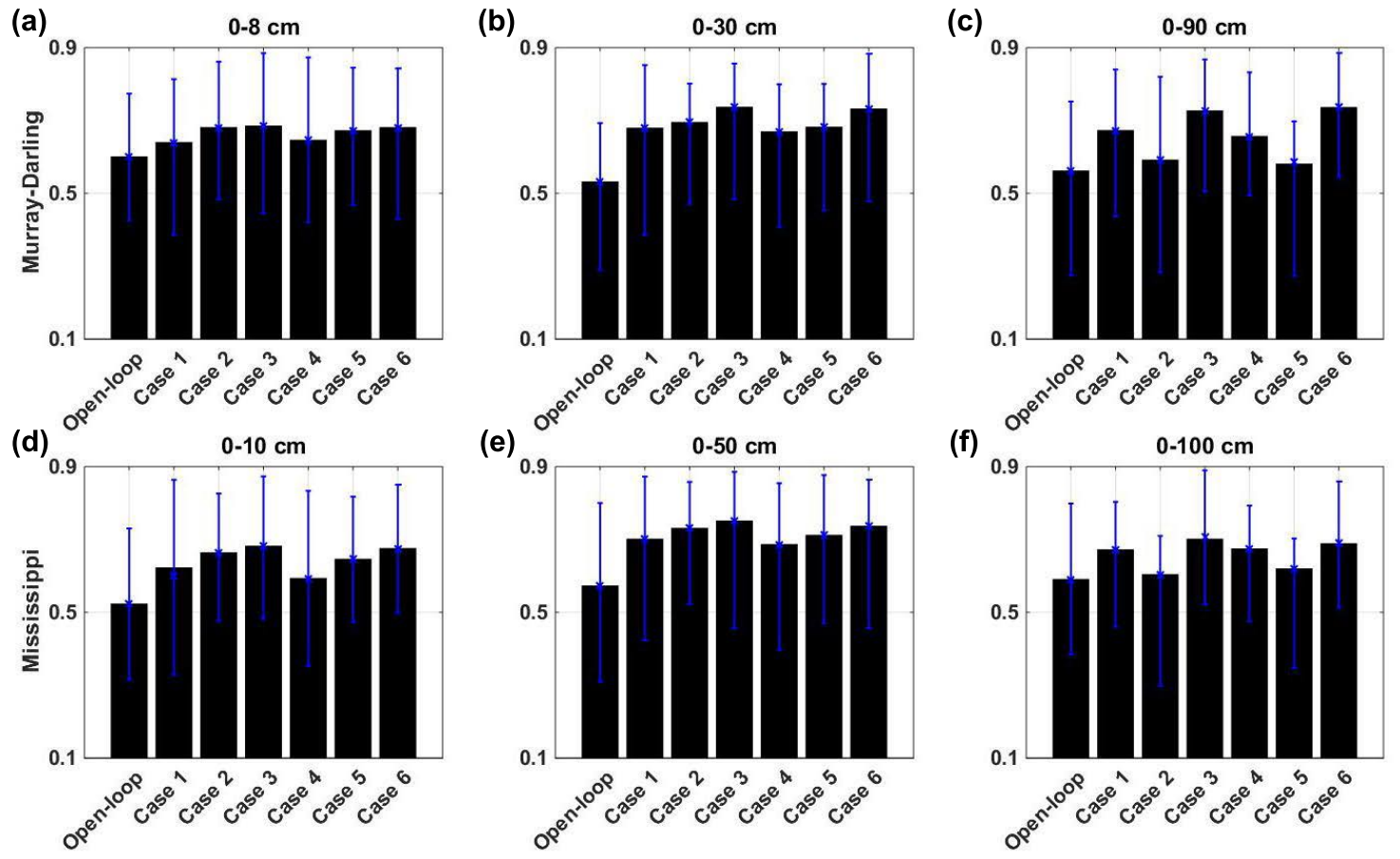

Figure 7: Average correlations between soil moisture estimated by each applied case and the open-loop run with in-situ measurements at different layers including 0-8 cm (a), 0-30 cm (b), and 0-90 cm (c) over the Murray-Darling basin, and 0-10 cm (a), 0-50 cm (b), and 0-100 cm (c) over the Mississippi basin.

or Kalman-Takens achieves the largest correlations to the in-situ measurements for all layers. This demonstrates the benefit of assimilating multiple data sets. Again, comparable results are obtained from both filtering schemes.

\subsection{Water fluxes assessment}

Comparison between estimated water storage changes, $\Delta \mathbf{s}$, and water fluxes, namely precipitation $\mathbf{p}$, evaporation $\mathbf{e}$, discharge $\mathbf{q}$, is assumed here. These components are related to each other in reality through the water balance equation (i.e., $\Delta \mathbf{s}=\mathbf{p}-\mathbf{e}-\mathbf{q}$ ). The correlation between the estimated $\Delta \mathbf{s}$ from all assimilation cases and each flux observation is calculated over the MurrayDarling and Mississippi basins. The average correlation values are presented in Figure 8. Larger correlations are obtained for assimilation cases compared to the open-loop run results. Smaller improvements are achieved from the assimilation of only soil moisture measurements in comparison to the GRACE, as well as simultaneous data assimilation. Similar to the previous results, it can be concluded that GRACE TWS has larger impacts on state estimates during data assimilation than 
(a)

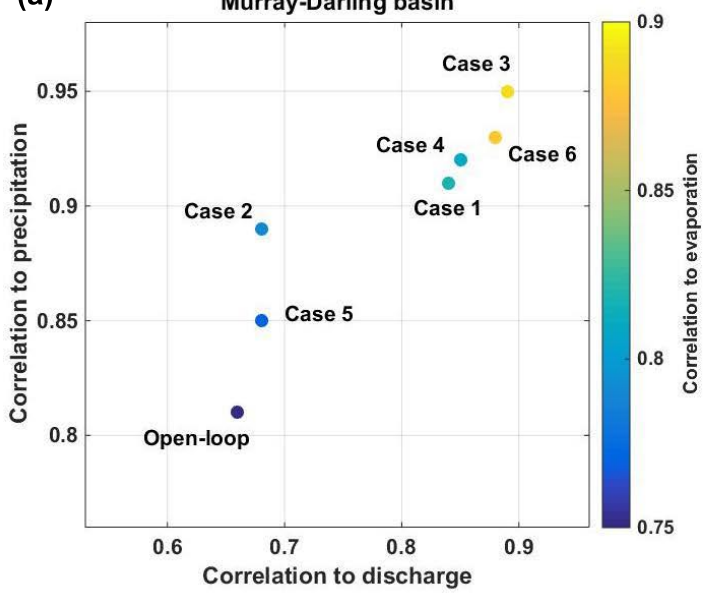

(b)

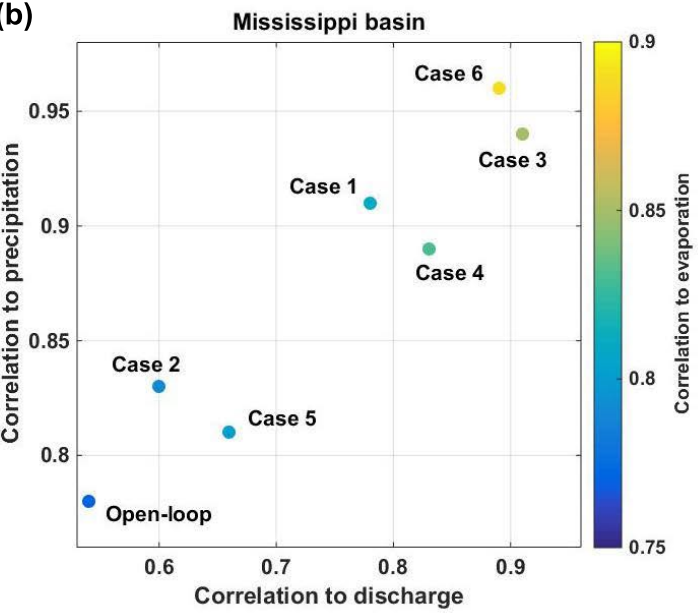

Figure 8: Average correlations between water storage changes, $\Delta \mathbf{s}$, estimated by each applied case and the open-loop run with water flux observations over the Murray-Darling (a) and Mississippi (b) basin.

Between flux observations, it is found that, in general, larger correlations are achieved between $\Delta \mathbf{s}$ and $\mathbf{p}$, which is due to the larger influences of rainfall on water storage variations over the basins. SQRA reaches higher correlation values to $\mathbf{q}$ over both basins. In terms of $\mathbf{p}$ and $\mathbf{e}$, on the other hand, the Kalman-Takens filter obtains larger correlations over the Mississippi basin. It can also be seen that larger correlation of $\Delta \mathbf{s}$ to $\mathbf{p}$, generally leads to larger correlation to $\mathbf{e}$ in different cases (e.g., simultaneous assimilation using SQRA and Kalman-Takens). From Figure 8, it is also clear that GRACE only data assimilation has better influences on the Murray-Darling basin, close to the simultaneous assimilation results. These results confirm previous outcomes that the KalmanTakens filter performs well during assimilation comparable to the standard data assimilation using SQRA.

\section{Discussion}

The results of Section 4 suggest that in all cases, assimilation improves groundwater estimates in comparison to the open-loop ( $\sim 38 \%$ RMSE reduction). Simultaneous data assimilations, i.e., simultaneous assimilations of observations using dynamical method (case 3) and the KalmanTakens (case 6) lead to the largest RMSE reductions of $41.27 \%$ with $39.07 \%$, respectively. This is in 
agreement with the founding of previous literature (see, e.g., Montzka et al., 2012; Renzullo et al., 2014; Zobitz et al., 2014; Tian et al., 2017), which suggested that better results can be achieved by assimilating multi-satellite products when properly accounting for the measurement errors. Larger impacts on results are found for assimilating GRACE compared to satellite soil moisture observations. This, in particular, is evident by monitoring data assimilation results against in-situ soil moisture networks with the Murray-Darling and Mississippi basins. More pronounced improvements (12\% on average) are obtained in the deep soil moisture layers, where GRACE TWS has the larger impacts on state estimates. Approximately 31\% improvements in groundwater estimations are obtained from GRACE TWS only (in cases 1 and 4) as compared to soil moisture assimilation in cases 2 and 5 regardless of the filtering method. A similar impact was also suggested by Khaki et al. (2017a). Overall, close performances are observed from the dynamical and data-driven approaches. Interestingly, the Kalman-Takens outperforms SQRA filter in some cases, e.g., 2.23\% more RMSE reduction over the Mississippi basin. Hamilton et al. (2016) explained that in cases where the model is subjected to larger errors, the Kalman-Takens could provide better forecasts. We further find that the Kalman-Takens is much less computationally demanding ( $\sim 6$ times faster $)$ compared to the standard SQRA implementation, which can be very important especially in cases with high spatio-temporal resolutions.

\section{Conclusion}

Assimilation of multi-mission satellite products can be achieved using model-based and data-driven techniques. We assimilate the Gravity Recovery And Climate Experiment (GRACE) terrestrial water storage (TWS) and soil moisture products from the Advanced Microwave Scanning Radiometer - Earth Observing System (AMSR-E) and Soil Moisture and Ocean Salinity (SMOS) using the Square Root Analysis (SQRA) and data-driven Kalman-Takens techniques to assess their performances. Independent groundwater and soil moisture in-situ measurements are used to examine the data assimilation results over the Murray-Darling and Mississippi basins. Our results indicate that in most of the cases, simultaneously assimilation of observations using either SQRA or Kalman-Takens provides the best results with respect to in-situ measurements. These variants can also better distribute the effects of observations between all state compartments such as different soil layers and groundwater. This is shown by the better agreement between assimilation results corresponding to cases 3 and 6 and both groundwater and soil moisture in-situ measurements. 
More improvements in both water components estimates are obtained within Mississippi basin, particularly using Kalman-Takens. This could be attributed to the larger model errors, which have larger impacts on the parametric method that uses model dynamics. It can be concluded that the Kalman-Takens can perform better for the cases the model is subject to error. In general, the performances of the data-driven Kalman-Takens approach are comparable to those of the standard SQRA. This study suggests that the data-driven filtering technique can be a capable alternative for the traditional data assimilation.

\section{References}

Anderson, J., (2001). An Ensemble Adjustment Kalman Filter for Data Assimilation. Mon. Wea. Rev., 129, 28842903, http://dx.doi.org/10.1175/1520-0493(2001)129;2884:AEAKFF ¿2.0.CO;2.

Anderson, M.C., Norman, J.M., Mecikalski, J.R., Otkin, J.A., Kustas, W.P., (2007). A climatological study of evapotranspiration and moisture stress across the continental United States based on thermal remote sensing: 1. Model formulation. J. Geophys. Res. 112 (D10117). http://dx.doi.org/10.1029/2006JD007506.

Awange, J.L., Mpelesoka, F., Goncalves, R.M., (2016). When every drop counts: Analysis of Droughts in Brazil for the 1901-2013 period. Science of the Total Environment, 566567, 14721488.

Bertino, L., Evensen G., Wackernagel, H., (2003). Sequential Data Assimilation Techniques in Oceanography, International Statistical Review, Vol. 71, No. 2 (Aug., 2003), pp. 223-241.

Bishop, C. H., Etherton, B., Majumdar, S. J., (2001). Adaptive sampling with the ensemble transform Kalman filter, Part I: theoretical aspects. Mon. Wea. Rev. 129, 420436.

Boening, C., Willis, J.K., Landerer, F.W., Nerem, R.S., Fasullo, J., (2012). The 2011 La Nia: so strong, the oceans fell. Geophys. Res. Lett. 39, L19602. http://dx.doi.org/10.1029/2012GL053055.

Burgers, G., van Leeuven, P.J., Evensen, G., (1998). Analysis scheme in the ensemble Kalman filter, Mon. Wea. Rev., 126, 17191724.

Cheng, M.K., Tapley, B.D., (2004). Variations in the Earth's oblateness during the past 28 years. Journal of Geophysical Research, Solid Earth, 109, B09402. http://dx.doi.org/10.1029/2004JB003028. 
Coumou, D., Rahmstorf, S., (2012). A decade of weather extremes Nat. Clim. Change, 2 (7), pp. 16.

Doll, P., Kaspar, F., Lehner, B., (2003). A global hydrological model for deriving water availability indicators: model tuning and validation, J. Hydrol., 270, 105134.

De Jeu, R.A.M., Owe, M., (2003). Further validation of a new methodology for surface moisture and vegetation optical depth retrieval. Int J Remote Sens 24:45594578, http://dx.doi.org/10.1080/0143116031000095934.

De Jeu, R.A.M., Wagner, W., Holmes, T.R.H., Dolman, A.J., van de Giesen , N.C., Friesen J., (2008) Global Soil Moisture Patterns Observed by Space Borne Microwave Radiometers and Scatterometers, Surveys in Geophysics,Volume 29, Issue 45, pp 399420, http://dx.doi.org/10.1007/s10712-008-9044-0.

Draper, C.S., Mahfouf, J.-F., Walker, J.P., (2009), An EKF assimilation of AMSRE soil moisture into the ISBA land surface scheme, J. Geophys. Res., 114, D20104, http://dx.doi.org/10.1029/2008JD011650.

Dreano, D., Mallick, B., Hoteit, I., (2015). Filtering remotely sensed chlorophyll concentrations in the Red Sea using a spacetime covariance model and a Kalman filter, Spatial Statistics, Volume 13, Pages 1-20, ISSN 2211-6753, http://dx.doi.org/10.1016/j.spasta.2015.04.002.

Drusch, M., Wood, E.F., Gao, H., (2005). Observation operators for the direct assimilation of TRMM microwave imager retrieved soil moisture. Geophysical Research Letters, 32, L15403.

Eicker, A., Schumacher, M., Kusche, J., Dll, P., Mller-Schmied, H., (2014). Calibration/data assimilation approach for integrating GRACE data into the WaterGAP global hydrology model (WGHM) using an ensemble Kalman filter: first results, SurvGeophys, 35(6):12851309. http://dx.doi.org/10.1007/s10712-014-9309-8.

Evensen, G., (2003). The ensemble Kalman filter: Theoretical formulation and practical inplementation, Ocean Dynamics, 53, 343367, http://dx.doi.org/10.1007/s10236-003-0036-9.

Evensen, G., (2004). Sampling strategies and square root analysis schemes for the EnKF. Ocean Dyn. 54(6), 539-560.

Evensen, G., (2007). Data Assimilation: The Ensemble Kalman Filter, Springer, 279 pp. 
Forootan, E., Khandu, Awange, J., Schumacher, M., Anyah, R., van Dijk, A., Kusche, J., (2016). Quantifying the impacts of ENSO and IOD on rain gauge and remotely sensed precipitation products over Australia. Remote Sensing of Environment,172, Pages 50-66, http://dx.doi.org/10.1016/j.rse.2015.10.027.

Giustarini, L., Matgen, P., Hostache, R., Montanari, M., Plaza, D., Pauwels, V.R.N., De Lannoy, G.J.M., De Keyser, R., Pfister, L., Hoffmann, L., Savenije, H.H.G., (2011). Assimilating SARderived water level data into a hydraulic model: a case study, Hydrol. Earth Syst. Sci., 15, 23492365, http://dx.doi.org/10.5194/hess-15-2349-2011.

Gutentag, E.D., Heimes, F.J., Krothe, N.C., Luckey, R.R., Weeks, J.B., (1984). Geohydrology of the High Plains aquifer in parts of Colorado, Kansas, Nebraska, New Mexico, Oklahoma, South Dakota, Texas, and Wyoming, U.S. Geol. Surv. Prof. Pap., 1400-B, 66 pp.

Hamilton, F., Berry, T., Sauer, T., (2016). Ensemble Kalman Filtering without a Model, Phys. Rev. X 6, 011021, Vol. 6, Iss. 1, http://dx.doi.org/10.1103/PhysRevX.6.011021.

Hamilton, F., Berry, T., Sauer, T., (2017). Kalman-Takens filtering in the presence of dynamical noise, To appear, Eur. Phys. J: ST.

Hoteit, I., Pham, D.T., Blum, J., (2002). A simplified reducedorder kalman filtering and application to altimetric data assimilation in tropical Pacific. J. Mar. Syst., 36, 101127.

Hoteit, I., Luo, X., Pham, D.T., (2012). Particle Kalman Filtering: A Nonlinear Bayesian Framework for Ensemble Kalman Filters, Monthly Weather Review, 140:2, 528-542.

Hoteit, I., Pham, D.T., Gharamti, M. E., Luo, X., (2015). Mitigating Observation Perturbation Sampling Errors in the Stochastic EnKF, Monthly Weather Review, 143:7, 2918-2936.

Houtekamer, P.L., Mitchell, H.L., (2001). A Sequential Ensemble Kalman Filter for Atmospheric Data Assimilation, Mon. Wea. Rev., 129:1, 123-137.

Huffman, G.J., Adler, R.F., Bolvin, D.T., Gu, G., Nelkin, E.J., Bowman, K.P., Hong, Y., Stocker, E.F., Wolff, D.B., (2007). The TRMM Multi-satellite Precipitation Analysis: Quasi- Global, Multi-Year, Combined-Sensor Precipitation Estimates at Fine Scale. J. Hydrometeor., 8(1), 3855. 
Huntington, T.G., (2006). Evidence for intensification of the global water cycle: Review and synthesis, J. Hydrol.,319(14), 8395, http://dx.doi.org/10.1016/j.jhydrol.2005.07.003.

Jackson, T., Bindlish, R., (2012). Validation of Soil Moisture And Ocean Salinity (SMOS) soil moisture over watershed networks in the US, IEEE Trans. Geosci. Remote Sens., 50, 15301543.

Jacquette, E., Al Bitar, A., Mialon, A., Kerr, Y., Quesney, A., Cabot, F., et al. (2010). SMOS CATDS level 3 global products over land. In C. M. U. Neale, A. Maltese (Eds.), Remote Sensing for Agriculture, Ecosystems, and Hydrology XII. volume 7824 of Proceedings of SPIE-The International Society for Optical Engineering. Conference on Remote Sensing for Agriculture, Ecosystems, and Hydrology XII, Toulouse, France.

Jing, W., Song, J., Zhao, X., (2018). A Comparison of ECV and SMOS Soil Moisture Products Based on OzNet Monitoring Network. Remote Sens., 10(5), 703; https://doi.org/10.3390/rs10050703.

Jones, D.A., Wang, W., Fawcett, R., Grant, I., (2007). Climate data for the Australian water availability project. In: Australian Water Availability Project Milestone Report. Bur. Met., Australia, 37pp.

Kalnay, E., (2003). Atmospheric modelling, data assimilation and predictability, Cambridge University Press. pp. xxii 341. ISBNs 052179179 0, 052179629 6. http://dx.doi.org/ $10.1256 / 00359000360683511$.

Khaki, M., Hoteit, I., Kuhn, M., Awange, J., Forootan, E., van Dijk, A.I.J.M., Schumacher, M., Pattiaratchi, C., (2017a). Assessing sequential data assimilation techniques for integrating GRACE data into a hydrological model, Advances in Water Resources, Volume 107, Pages 301-316, ISSN 0309-1708, http://dx.doi.org/10.1016/j.advwatres.2017.07.001.

Khaki, M., Schumacher, M., J., Forootan, Kuhn, M., Awange, E., van Dijk, A.I.J.M., (2017b). Accounting for Spatial Correlation Errors in the Assimilation of GRACE into Hydrological Models through localization, Advances in Water Resources, Available online 1 August 2017, ISSN 0309-1708, https://doi.org/10.1016/j.advwatres.2017.07.024.

Khaki, M., Ait-El-Fquih, B., Hoteit, I., Forootan, E., Awange, J., Kuhn, M., (2017c). A Twoupdate Ensemble Kalman Filter for Land Hydrological Data Assimilation with an Uncer- 
tain Constraint, Journal of Hydrology, Available online 25 October 2017, ISSN 0022-1694, https://doi.org/10.1016/j.jhydrol.2017.10.032.

Khaki, M., Forootan, E., Kuhn, M., Awange, J., Papa, F., Shum, C.K., (2018a). A Study of Bangladesh's Sub-surface Water Storages Using Satellite Products and Data Assimilation Scheme. Science of The Total Environment, 625:963-977, https://doi.org/10.1016/j.scitotenv.2017.12.289.

Khaki, M., Forootan, E., Kuhn, M., Awange, J., van Dijk, A.I.J.M., Schumacher, M., Sharifi, M.A., (2018b). Determining Water Storage Depletion within Iran by Assimilating GRACE data into the W3RA Hydrological Model. Advances in Water Resources, 114:1-18, https://doi.org/10.1016/j.advwatres.2018.02.008.

Khaki, M., Forootan, E., Kuhn, M., Awange, J., Longuevergne, L., Wada, W., (2018c). Efficient Basin Scale Filtering of GRACE Satellite Products, In Remote Sensing of Environment, Volume 204, Pages 76-93, ISSN 0034-4257, https://doi.org/10.1016/j.rse.2017.10.040.

Khaki, M., Hamilton, F., Forootan, E., Hoteit, I., Awange, J., Kuhn, M., (2018d). Nonparametric Data Assimilation Scheme for Land Hydrological Applications, Water Resour. Res.. https://doi.org/10.1029/2018WR022854.

Khaki, M., Ait-El-Fquih, B., Hoteit, I., Forootan, E., Awange, J., Kuhn, M., (2018e). Unsupervised ensemble Kalman filtering with an uncertain constraint for land hydrological data assimilation, In Journal of Hydrology, Volume 564, Pages 175-190, ISSN 0022-1694, https://doi.org/10.1016/j.jhydrol.2018.06.080.

Kumar, S.V., Reichle, R.H., Harrison, K.W., Peters-Lidard, C.D., Yatheendradas, S., Santanello, J.A., (2012). A comparison of methods for a priori bias correction in soil moisture data assimilation, Water Resour. Res., 48, W03515, http://dx.doi.org/10.1029/2010WR010261.

Leroux, D.J., Pellarin, T., Vischel, T., Cohard, J.-M., Gascon, T., Gibon, F., Mialon, A., Galle, S., Peugeot, C., Seguis, L., (2016). Assimilation of SMOS soil moisture into a distributed hydrological model and impacts on the water cycle variables over the Oum catchment in Benin, Hydrol. Earth Syst. Sci., 20, 2827-2840, https://doi.org/10.5194/hess-20-2827-2016.

Lguensat, R., Tandeo, P., Ailliot, P., Pulido, M., Fablet, R., (2017). The Analog Data Assimilation. Mon. Wea. Rev., https://doi.org/10.1175/MWR-D-16-0441.1. 
Mayer-Gurr, T., Zehentner, N., Klinger, B., Kvas, A., (2014). ITSG-Grace2014: a new GRACE gravity field release computed in Graz. - in: GRACE Science Team Meeting (GSTM), Potsdam am: 29.09.2014.

Massari, C., Camici, S., Ciabatta, L., Brocca, L., (2018). Exploiting Satellite-Based Surface Soil Moisture for Flood Forecasting in the Mediterranean Area: State Update Versus Rainfall Correction. Remote Sensing, 10(2), 292.

Mladenova, I., Lakshmi, V., Jackson, T.J., Walker, J.P., Merlin, O., de Jeu, R.A.M., (2011). Validation of AMSR-E soil moisture using L-band airborne radiometer data from National Airborne Field Experiment 2006, Remote Sensing of Environment (2011), https://doi.org/10.1016/j.rse.2011.04.011

Montzka, C., Pauwels, V.R.N., Franssen, H.-J.H., Han, X., Vereecken, H., (2012). Multivariate and Multiscale Data Assimilation in Terrestrial Systems: A Review. Sensors 2012, 12, 16291-16333.

Mu, Q., Zhao, M., Running, S.W., (2011). Improvements to a MODIS Global Terrestrial Evapotranspiration Algorithm. Remote Sensing of Environment 115: 1781-1800.

Munoz, S.E., Dee, S.G., (2017). El Nio increases the risk of lower Mississippi River flooding, Scientific Reportsvolume 7, Article number: 1772, https://doi.org/10.1038/s41598-017-01919-6.

Neal, J., Schumann, G., Bates, P., Buytaert, W., Matgen, P., Pappenberger, F., (2009). A data assimilation approach to discharge esti- mation from space, Hydrol. Process., 23, 36413649.

Nerger, L., (2004). Parallel Filter Algorithms for Data Assimilation in Oceanography, PhD Thesis, University of Bremen.

Njoku, E.G. et al. (2003). Soil moisture retreival from AMSR-e. IEEE Transactions on Geo-science and Remote Sensing. 41:2, 215-229.

Njoku, E.G., (2004). AMSR-E/Aqua Daily L3 Surface Soil Moisture, Interpretive Parameters, QC EASE-Grids. Version 2. [indicate subset used]. Boulder, Colorado USA: NASA National Snow and Ice Data Center Distributed Active Archive Center. doi: 10.5067/AMSR-E/AE_LAND3.002.

Ott, E., Hunt, B.R., Szunyogh, I., Zimin, A.V., Kostelich, E.J., Corazza, M., Kalnay, E., Patil, D.J., Yorke, J.A., (2004). A local ensemble Kalman Filter for atmospheric data assimilation. Tellus, 56A: 415-428. 
Packard, N.H., Crutchfield, J.P., Farmer, J.D., Shaw, R.S., (1980). Geometry from a Time Series, Phys. Rev. Lett. 45, 712.

Peischl, S., Walker, J.P., Rdiger, C., Ye, N., Kerr, Y.H., Kim, E., Bandara, R., Allahmoradi, M., (2012). The AACES field experiments: SMOS calibration and validation across the Murrumbidgee River catchment, Hydrol. Earth Syst. Sci., 16, 1697-1708, https://doi.org/10.5194/hess-16-1697-2012, 2012.

Reager, J.T., Thomas, A.C., Sproles, E.A., Rodell, M., Beaudoing, H.K., Li, B., Famiglietti, J.S., (2015). Assimilation of GRACE Terrestrial Water Storage Observations into a Land Surface Model for the Assessment of Regional Flood Potential. Remote Sens. 2015, 7, 14663-14679.

Reichle, R.H., McLaughlin, D.B., Entekhabi, D., (2002). Hydrologic Data Assimilation with the Ensemble Kalman Filter. Mon. Wea. Rev. 130, 103114, http://dx.doi.org/10.1175/15200493(2002)130;0103:HDAWTE;2.0.CO;2.

Reichle, R.H., Koster, R.D., (2004). Bias reduction in short records of satellite soil moisture, Geophys. Res. Lett., 31, L19501, http://dx.doi.org/10.1029/2004GL020938.

Renzullo, L.J., Van Dijk, A.I.J.M., Perraud, J.M., Collins, D., Henderson, B., Jin, H., Smith, A.B., McJannet, D.L., (2014). Continental satellite soil moisture data assimilation improves root-zone moisture analysis for water resources assessment. J. Hydrol., 519, 27472762. http://dx.doi.org/10.1016/j.jhydrol.2014.08.008.

Sakov, P., Oke, P.R., (2008). A deterministic formulation of the ensemble Kalman filter: an alternative to ensemble square root filters, Tellus 60A, 361371.

Sauer, T., Yorke, J., Casdagli, M., (1991). Embedology, J. Stat. Phys. 65, 579.

Sauer, T., (2004). Reconstruction of Shared Nonlinear Dynamics in a Network, Phys. Rev. Lett. 93, 198701 .

Schumacher, M., Kusche, J., Dll, P., (2016). A systematic impact assessment of GRACE error correlation on data assimilation in hydrological models, Journal of Geodesy, http://dx.doi.org/10.1007/s00190-016-0892-y.

Seo, D.J., Koren, V., Cajina, N., (2003). Real-time variational assimilation of hydrologic and hydrometeorological data into operational hydrologic forecasting. J. Hydrometeorol., 4, 627641. 
Seoane, L., Ramillien, G., Frappart, F., Leblanc, M., (2013). Regional GRACE-based estimates of water mass variations over Australia: validation and interpretation, Hydrol. Earth Syst. Sci., 17, 4925-4939, http://dx.doi.org/10.5194/hess-17-4925-2013.

Sheffield, J., Goteti, G., Wood, E. F., (2006). Development of a 50-yearhigh-resolution global dataset of meteorological forcings for land surfacemodeling, J. Clim., 19(13), 30883111.

Schneider, U., Fuchs, T., Meyer-Christoffer, A., Rudolf, B., (2008). In G. P. C. Centre (Ed.), Internet publication.

Schumacher, M., Kusche, J., Dll, P., (2016). A systematic impact assessment of GRACE error correlation on data assimilation in hydrological models, Journal of Geodesy, http://dx.doi.org/10.1007/s00190-016-0892-y.

Strassberg, G., Scanlon, B.R., Rodell, M., (2007). Comparison of seasonal terrestrial water storage variations from GRACE with groundwater-level measurements from the High Plains Aquifer (USA), Geophys. Res. Lett., 34, L14402, http://dx.doi.org/10.1029/2007GL030139.

Su, C.-H., Ryu, D., Young, R.I., Western, A.W., Wagner, W., (2013). Inter-comparison of microwave satellite soil moisture retrievals over the Murrumbidgee Basin, southeast Australia. Remote Sensing of Environment, 134, 111.

Swenson, S., Chambers, D., Wahr, J., (2008). Estimating geocentervariations from a combination of GRACE and ocean model output. Journal of Geophysical research, 113, B08410, http://dx.doi.org/10.1029/2007JB005338.

Takens, F., (1981). Dynamical Systems and Turbulence, Warwick 1980, Lect. Notes Math. 898, 366.

Tandeo, P., Coauthors, (2015). Combining analog method and ensemble data assimilation: application to the lorenz-63 chaotic system. Machine Learning and Data Mining Approaches to Climate Science, Springer, 312 .

Tangdamrongsub, N., Han, S.-C., Tian, S., Mller Schmied, H., Sutanudjaja, E.H., Ran, J., Feng, W., (2018). Evaluation of Groundwater Storage Variations Estimated from GRACE Data Assimilation and State-of-the-Art Land Surface Models in Australia and the North China Plain. Remote Sens., 10, 483. 
Thomas, A.C., Reager, J.T., Famiglietti, J.S., Rodell, M., (2014). A GRACE-based water storage deficit approach for hydrological drought characterization. Geophys. Res. Lett. 41, 15371545.

Tian, S., Tregoning, P., Renzullo, L.J., van Dijk, A.I.J.M., Walker, J.P., Pauwels, V.R.N., Allgeyer, S., (2017). Improved water balance component estimates through joint assimilation of GRACE water storage and SMOS soil moisture retrievals, Water Resour. Res., 53, http://dx.doi.org/10.1002/2016WR019641.

Tippett, M.K., Anderson, J.L., Bishop, C.H., Hamill, T.M., Whitaker, J.S., (2003). Ensemble square root filters, Mon. Weath. Rev., 131, 148590.

Tropical Rainfall Measuring Mission (TRMM), (2011). TRMM (TMPA/3B43) Rainfall Estimate L3 1 month 0.25 degree x 0.25 degree V7, Greenbelt, MD, Goddard Earth Sciences Data and Information Services Center (GES DISC), Accessed [Data Access Date] https://disc.gsfc.nasa.gov/datacollection/TRMM_3B43_7.html.

van Dijk, A.I.J.M., (2010). The Australian Water Resources Assessment System: Technical Report 3, Landscape model (version 0.5) Technical Description, CSIRO: Water for a Healthy Country National Research Flagship.

van Dijk, A.I.J.M., Renzullo, L.J., and Rodell, M., (2011). Use of Gravity Recovery and Climate Experiment terrestrial water storage retrievals to evaluate model estimates by the Australian water resources assessment system, Water Resour. Res., 47, W11524, http://dx.doi.org/10.1029/2011WR010714.

van Dijk, A.I.J.M., Pea-Arancibia, J.L., Wood, E.F., Sheffield, J., Beck, H.E., (2013). Global analysis of seasonal streamflow predictability using an ensemble prediction system and observations from 6192 small catchments worldwide, Water Resour. Res., 49, 27292746, http://dx.doi.org/10.1002/wrcr.20251.

Vrugt, J.A., Diks, C.G., Gupta, H.V., Bouten, W., Verstraten, J.M., 2005. Improved treatment of uncertainty in hydrologic modeling: Combining the strengths of global optimization and data assimilation. Water Resour. Res, 41, W01017, http://dx.doi.org/10.1029/2004WR003059.

Vrugt, J.A., ter Braak, C.J.F., Diks, C.G.H., Schoups, G., (2013). Advancing hydrologic data assimilation using particle Markov chain Monte Carlo simulation: theory, concepts 
and applications, Advances in Water Resources, Anniversary Issue - 35 Years, 51, 457-478, http://dx.doi.org/10.1016/j.advwatres.2012.04.002.

Wahr, J.M., Molenaar, M., Bryan, F., (1998). Time variability of the Earth's gravity field: hydrological and oceanic effects and their possible detection using GRACE. J Geophys Res 108(B12):3020530229, http://dx.doi.org/10.1029/98JB02844.

Weerts, A.H., El Serafy, G.Y.H., (2006). Particle filtering and ensemble Kalman filtering for state updating with hydrological conceptual rainfall-runoff models. Water Resour. Res., 42, W09403, http://10.1029/2005WR004093.

Whitaker, J.S., Hamill, T.M., (2002). Ensemble data assimilation without perturbed observations, Mon. Wea. Rev., 130, 19131924.

Wooldridge, S.A., Kalma, J.D., (2001). Regional-scale hydrological modelling using multipleparameter landscape zones and a quasi-distributed water balance model. Hydrological Earth System Sciences. 5: 59-74.

Zaitchik, B.F., Rodell, M., Reichle, R.H., (2008). Assimilation of GRACE terrestrial water storage data into a land surface model: results for the Mississippi River Basin. J Hydrometeorol 9(3):535548, http://dx.doi.org/10.1175/2007JHM951.1.

Zobitz, J.M., Moore, D.J.P., Quaife, T., Braswell, B.H., Bergeson, A., Anthony, J.A., Monson, R.K., (2014). Joint data assimilation of satellite reflectance and net ecosystem exchange data constrains ecosystem carbon fluxes at a high-elevation subalpine forest, Agricultural and Forest Meteorology, Volumes 195196, 15 , Pages 73-88, ISSN 0168-1923, https://doi.org/10.1016/j.agrformet.2014.04.011. 